\title{
Factors Affecting Happiness of School Children
}

\author{
Munevver Mertoğlu \\ Correspondence: Munevver Mertoğlu, Istanbul Culture University, Center of Cehamer, The Head of Violence Research \\ and Prevention Section, Istanbul, Turkey.
}

Received: November 18, 2019

doi:10.11114/jets.v8i3.4674

\author{
Accepted: December 18, 2019 \\ Online Published: January 3, 2020 \\ URL: https://doi.org/10.11114/jets.v8i3.4674
}

\begin{abstract}
Parents, teachers and managers are crucial elements and play a key role in raising happy and healthy individuals. Besides the factors that determine the level of happiness, turning happiness into something that can be taught puts responsibility on people who are accountable for raising children starting from first-year education. Our study aims to offer suggestions to contribute to students' happiness by determining variables which affect the level of happiness of students whose study levels vary from 3rd grade to 12th grade. Sample space is composed of 2187 students in total and 28 different schools located in İzmir-Dikili and Foça district. "School Children Happiness Inventory" was used to measure students' happiness levels. "One Way ANOVA", "t-test", "Varian's Homogeneity Test", Welch and Post-hoc tests are used for the statistical analysis of data. The results of the statistical analysis have illustrated that students' happiness score does not depend on grade, the number of siblings, financial situation, whether a mother is working or mother's job type. On the other hand, it has seen that happiness score decreases when a father is unemployed, and parents are divorced. Other important data shows that happiness score decreases as students get older. Findings have demonstrated that enjoying going to school, spending quality time with their peers and having fun with them as well as having higher self-esteem and feeling safe in school environment contribute to the level of happiness of students in a positive way. A necessary suggestion has been provided to contribute to students' level of happiness.
\end{abstract}

Keywords: happiness, student, safe school, self-esteem, teacher, parent

\section{Introduction}

Social welfare and happiness can be achieved only by raising happy and productive individuals for society. Although it shows some variations depending on the culture, almost every society aims to have healthy and happy individuals as well as being concerned about their academic success. (1739 Basic Law of National Education- 1973)

According to Child Rights Agreement, child's best interests are fundamental (Convention of the rights of the child, article 3-1995). The notion of a child's best interest describes wellbeing, happiness and the health of a child (Turkish Linguistic Society). The agreement also states that in order for the child's personality to develop fully and in harmony, happiness, love and understanding are necessary elements in a family.

The Same conditions are expected to be maintained in a school environment. While countries which abide by Child's Rights Agreement regulate their education system's requirements, they must also determine objectives that help children grow up in a loving environment.

The second paragraph of Article 3 of the General Objectives of the Basic Law of National Education No. 1739 regulating the Turkish Education System states that the aim is to increase the welfare and happiness of Turkish citizens and the Turkish society. Emphasizing the happiness of Turkish citizens and then the Turkish community in general purposes at all levels of education.

Achieving the goal of "educating happy individuals" in the education system may not always be easy because there are many factors that affect children, particularly teenagers, outside schooling;

Family, school, environment, genetic and neurologic factors, social and economic reasons and health can be considered as main factors (Holder \& Coleman, 2009)

Especially, factors affecting children's happiness in family and school need to be known. Research in this area will help to develop strategies needed to train happy individuals and help people who are responsible for child care and education such as parents, teachers and school managers. Therefore, our study has significant importance in terms of determining reasons affecting a child's happiness and proposes measures that can be taken. 
When the literature is examined, it can be seen that the definition of happiness is related to concepts like "pleasure", "being healthy", "life satisfaction", "flow", "subjective well-being" and "having positive feelings" (Diener, Oishi, \& Lucas, 2003; Eryilmaz, 2012)

Lately, there has been a research on neurological, hormonal and genetic tendency to happiness (Knutson, Taylor, Kaufman, Peterson, \& Glover, 2005; Lyubomirsky, S., Sheldon, K. M., \& Schkade, D. 2005; Myers, D. G. \& Diener, E. 1995; Deci, E. L., \& Ryan, R. M. 2000; Deneve, K. M., \& Cooper, H. 1998 Diener, E. 2000). Moreover, studies on analysing the relationship of a child with family and their environment and how these affect their level of happiness shows that people who are raising a child are not helpless (Uusitalo-Malmivaara \& Lehto, 2013).

For instance, studies showing that being hopeful and optimistic make individuals happy are encouraging, as they show that students can be made happy.

Studies illustrating the fact that it makes people happy to see health as a blessing, and remember and list things are crucial in terms of showing the cognitive dimension of happiness and that it is something that can be learned. (Emmons, Shelton, 2002).

Nowadays, positive psychology-based intervention programs are particularly effective in the happiness of adolescents (Shoshani and Steinmetz, 2014).

Studies showing a significant correlation between a student's subjective well-being and academic achievement at school cannot determine whether the student is happy because they are successful, or they are successful because they are happy (Cheng \& Furnham, 2002; Huebner \& Alderman, 1993). However, these studies are important as they are emphasizing the role of happiness in the academic success.

Besides the fact that happiness has to do with academic success, it is also associated with countless successful results where they come first. This points out the fact that happiness can lead to success in different areas (Diener et al., 2003) (Lyubomirsky, King, \& Diener 2005).

\section{Purpose and Research Questions}

By determining the happiness level and variables that affect the happiness of the students in the 3rd to 12th grade, suggestions are made to individuals who are responsible for raising these children.

Questions asked in this research:

-What is the happiness level of students? What topics do make students happy or unhappy? (According to the topics defined in happiness scale)

- What are the factors affecting students' happiness? Do those factors change depending on grades, how many children there are in the family, financial situation, whether mother is unemployed or not, what type of job she is doing, whether father is unemployed or not, what type of job he is doing and whether mother and father can get along well or divorced?

\section{Methodology}

\section{Sampling}

Purposeful sampling method was used in the study. Secondary schools, which were requested by İzmir-Foça and Dikili District Governorship from İstanbul Kultur University and which carried out "The Healthy, Happy and Successful School to Teacher Project "conducted by the author, were included in the sample group.

Sample space is composed of 2187 students who are at 3rd to 12th grade studying 28 different schools in Dikili and Foça district.

"School Children Happiness Inventory" was used to measure children's happiness level. Validity and Reliability study was conducted by Bülent Baki Telef (Telef, B. B. (2014). After the reliability analysis of the inventory, the Cronbach's alpha coefficient of the School Children's Happiness Inventory was determined as .92. After the item analysis, total correlations of the items were found to be .30 and higher and it was also found that $t$ values were significant.

"One Way ANOVA", "t-test", "Variations Homogeneity Test", Welch and Tamhane Test were used for the statistical analysis of data.

\section{Findings}

\section{Research Question 1: What are the general happiness scores of students?}

15 of the 30 articles in School Children Happiness Inventory are designed as positive and remaining articles are negative. According to this, the high score received from positive items indicates a great level of happiness whereas high score received from negative items indicates a huge level of unhappiness. 
In order to determine the subjects that make students happy or unhappy, answers were averaged. To make presentation understandable, average scores received from positive items and average scores received from negative items are illustrated in two different tables. In both tables, the average scores are ordered from highest to lowest.

Table 1. Average scores received from positive items in happiness inventory

\begin{tabular}{|c|c|c|}
\hline Positive Items & Average & Std. Dev. \\
\hline 30. I liked being with other people & 3,37 & ,958 \\
\hline 23. I had self confidence & 3,35 & ,931 \\
\hline 3. I wanted to come to the school & 3,32 & 1,016 \\
\hline 16. I had fun & 3,30 & ,983 \\
\hline 8. I felt the school was safe. & 3,26 & 1,032 \\
\hline 14I got along well with everyone & 3,24 & ,910 \\
\hline 21. I felt good & 3,24 & ,973 \\
\hline 1. I was full of energy & 3,23 & ,909 \\
\hline 19. I was willing to study & 3,19 & 1,002 \\
\hline 9. I could pay attention & 3,18 & ,944 \\
\hline 11. I felt positive & 3,16 & ,990 \\
\hline 28. I studied hard & 3,16 & ,960 \\
\hline 18. I was calm & 3,08 & 1,013 \\
\hline 26. I felt very lively & 3,04 & 1,061 \\
\hline 6. I was relaxed & 3,03 & 1,062 \\
\hline
\end{tabular}

As Table 1 illustrates, students received 3.03 and higher average scores from positive items. Considering that the highest score that can be received from the School Children Happiness Inventory is for 4, it can be said that the happiness level of children is high. The 5 top subjects making students happy are as following; "Enjoying being with other people", "Having self-confidence", "Wanting to go to school", "Having fun", "Feeling a school is a safe place". 
Table 2. Average scores received from negative items in happiness inventory

\begin{tabular}{|c|c|c|}
\hline Negative items & Average & Std. Dev. \\
\hline 17. I was tired & 2,46 & 1,139 \\
\hline 22. I was confused & 2,25 & 1,137 \\
\hline 27. I had a headache & 2,00 & 1,141 \\
\hline 2. I was nervous & 1,98 & 1,057 \\
\hline 10. I was unpleasant & 1,92 & 1,076 \\
\hline 7. I was sick & 1,90 & 1,094 \\
\hline 20. I felt sorry for myself & 1,82 & 1,092 \\
\hline 5. I was sorry & 1,80 & 1,046 \\
\hline 24. I was unhappy & 1,78 & 1,066 \\
\hline 12. I was angry & 1,76 & 1,032 \\
\hline 13. I wanted to cry & 1,69 & 1,054 \\
\hline 15. I was in a bad mood & 1,65 & 1,010 \\
\hline 25. I wanted to give up & 1,62 & 1,014 \\
\hline 4. was tetchy & 1,55 & ,915 \\
\hline 29. I felt scared & 1,54 & ,929 \\
\hline
\end{tabular}

As table 2 demonstrates, students received low average scores with the highest average score of 2.46. This result points out that unhappiness level of students is generally below average. The 5 top subjects making students unhappy can be listed as following; "being tired", "confusion", "having a headache", "being nervous", "being unpleasant".

Research Question 2: What factors do affect happiness of students?

In this section, difference tests were applied in order to find out how students' level of happiness shows variations depending on different factors such as their grade, the number of siblings, the number of children, the financial status of the family, whether mother works or not, whether father works or not, whether parents are divorced and whether parents are getting along well. Difference tests were applied to take the average of 30 items in "School Children Happiness Inventory". When averages are calculated, answers of 15 negative items are coded in reversed (item numbers: 2,4, 5, 7, $10,12,13,15,17,20,22,24,25,27,29)$.

3.a Does Students' Happiness Differ According to Class They Are in?

Table 3. Variations homogeneity test for classes

\begin{tabular}{lllll}
\hline & Levene Statistic & sd1 & sd2 & p \\
\hline Happiness & 3,571 & 8 & 2142 & \multirow{2}{*}{000} \\
\hline
\end{tabular}


Table 4. Difference in students' happiness depending on the grade they are at

\begin{tabular}{lllllll}
\hline & Grade & N & Average & Ss & Welch & p \\
\hline \multirow{4}{*}{ Happines } & 3rd/4thgrade & 364 & 3,40 &, 423 & \multirow{2}{*}{$, 49,277$} & \multirow{2}{*}{000} \\
& 5th grade & 312 & 3,33 &, 486 & & \\
& 6th grade & 398 & 3,29 &, 494 & & \\
& 7th grade & 321 & 3,25 &, 467 & & \\
8th grade & 302 & 3,08 &, 519 & & \\
9th grade & 127 & 2,99 &, 497 & & \\
10th grade & 143 & 2,85 &, 487 & & \\
11th grade & 98 & 2,73 &, 608 & & \\
12th grade & 86 & 2,57 &, 578 & &
\end{tabular}

Students are from 3rd to 12th grade. Except for 9 students who are in the 3rd grade, the number of students with higher grades is above 30. As there are a few students at 3rd grade, these students are grouped with the students at 4th grade and named as "3rd and 4th grade". The average happiness scores of grades are compared through one-way ANOVA.

Before one-way ANOVA was applied, variations homogeneity test was applied. As variations determined were not homogenous (Levene statistics $=3.571 ; \mathrm{ss} 1=8 ; \mathrm{sd} 2=2142 ; \mathrm{p}<0.0001$, see also Table 3 ), the Welch test was applied as an alternative to $\mathrm{F}$ test.

According to results, there is no difference in students at different grades in terms of their happiness score (Welch $=$ 49,277; $p>0,001$; see also Table 4).

In order to determine the difference between grades "Tamhane Test" is applied. It is observed that there is a significant decrease in the level of happiness as students at a higher grade.

According to this, scores of 3rd and 4th-grade students do not differ with great extent statistically compared with 5th-grade students. However, 3rd and 4th-grade students are much happier than 6., 7., 8., 9., 10., 11., and 12th-grade students.

There is no statistical difference in happiness scores of 5th-grade students and 6th and 7th grades students, however, 5th-grade students are statistically much happier than the 8., 9., 10., 11., and 12th-grade students.

There is no statistical difference in happiness scores of 6th-grade students and 7th grades students, however, 6th-grade students are statistically much happier than the 8., 9., 10., 11., and 12th-grade students.

7th-grade students are statistically much happier than the 8., 9., 10., 11., and 12th-grade students.

There is no statistical difference in happiness scores of 8th-grade students and 9th grades students, however, 8th-grade students are statistically much happier than the 10., 11., and 12th-grade students.

There is no statically difference in happiness scores of 9th-grade students and 10th grades students, however, 9th-grade students are statistically much happier than the 11., and 12th-grade students.

There is no statistical difference in happiness scores of 10th-grade students and 11th grades students, however, 10th-grade students are statistically much happier than the 12th-grade students

There is no statistical difference in happiness scores of 11th-grade students and 12th grades students.

These results indicate that students feel unhappier as they are enrolling in higher grades.

3.b Does Students' Happiness Differ According to the Number of Siblings?

The number of siblings is categorized into 4 groups. 42 students did not answer the question about the number of siblings. Therefore, comparisons made based on 2127 students.

In order to test whether students' happiness varies depending on the number of siblings, one-way ANOVA test is applied. 
Table 5. Variations Homogeneity Test for Students' number of siblings

\begin{tabular}{lllll}
\hline & Levene Statistic & sd1 & sd2 & p \\
\hline Happiness & 0.146 & 3 & 2123 & .932 \\
\hline
\end{tabular}

Table 6. Difference in happiness depending on the number of siblings

\begin{tabular}{lllllll}
\hline & Number of siblings & $\mathbf{N}$ & Average & $\begin{array}{l}\text { Std. } \\
\text { Dev. }\end{array}$ & F & p \\
\hline \multirow{3}{*}{ Happiness } & 1 sibling & 281 & 3.18 & .538 & 1.799 & .145 \\
& 2 siblings & 1055 & 3.20 & .539 & & \\
& 3 siblings & 475 & 3.20 & .522 & & \\
& 4 or more siblings & 316 & 3.12 & .536 & &
\end{tabular}

Before one-way ANOVA was applied, variations homogeneity test had applied. As variations determined as homogenous (Levene statistics $=0.146 ; \mathrm{ss} 1=8 ; \mathrm{sd} 2=2142 ; \mathrm{p}<0.0001$, see also Table 8), F test is applied.

According to the statistical analysis, there is no statistical difference in happiness scores of students depending on the number of siblings ( $\mathrm{F}=1,799 ; \mathrm{p}>0,05$; see also Table 5).

\section{3.c Does Students' Happiness Differ According to Being Older or Younger Sibling in the Family?}

Whether students are older or younger siblings is categorized into 4 groups. 42 students did not answer the question about whether they are older or younger sibling. Therefore, comparisons made based on 2018 students.

In order to test whether students' happiness varies depending on they are older or younger siblings; one-way ANOVA test is applied.

Before one-way ANOVA was applied, variations homogeneity test was applied. As variations determined as homogenous (Levene statistics $=0.941 ; \mathrm{ss} 1=3 ; \mathrm{sd} 2=2014 ; \mathrm{p}<0.05$, see also Table 7), F test is applied.

Table 7. Variation Homogeneity Test according to whether students older or younger sibling in the family

\begin{tabular}{lllll}
\hline & Levene Statistics & sd1 & sd2 & p \\
\hline Happiness & 0.941 & 3 & 2014 & .420
\end{tabular}

Table 8. Difference in happiness scores of students depending on whether they are older or younger sibling in the family

\begin{tabular}{lllllll}
\hline & Order of siblings & $\mathbf{N}$ & Average & ss & $\mathbf{F}$ & $\mathbf{p}$ \\
\hline \multirow{3}{*}{ Happiness } & 1st child & 955 & 3.20 & .535 & \multirow{2}{*}{1.652} & .17 \\
& 2nd child & 716 & 3.19 & .546 & & \\
& 3rd child & 218 & 3.11 & .530 & & \\
& 4th or more & 129 & 3.21 & .479 & & \\
\hline
\end{tabular}

According to the statistical analysis, there is no statistical difference in happiness scores of students depending whether they are older or younger siblings in the family $(\mathrm{F}=1.652 ; \mathrm{p}>0,05$; see also Table 8$)$.

\section{3.d Does Students' Happiness Differ According to the Financial Situation of Their Family?}

The financial situation of students' family is categorized into 3 groups. 34 students did not answer this question. Therefore, comparisons are made based on 2135 students.

In order to test whether students' happiness varies depending on their financial situation, one-way ANOVA test is applied.

In order to determine which groups, have the difference, Tamhane test is applied (see also Table 14). According to this, students whose families have better financial status are much happier than those whose financial situation is average or worse. On the other hand, there is no difference in the happiness level of students whose families' financial situation is average and students whose families' financial status is worse. 
Table 9. Variation Homogeneity test for students' family's financial status

\begin{tabular}{lllll}
\hline & Levene Statistic & sd1 & sd2 & P \\
\hline Happiness & 5.700 & 2 & 2132 & .003 \\
\hline
\end{tabular}

Table 10. The difference in happiness according to families' financial status

\begin{tabular}{lllllll}
\hline & Financial Status of Family & N & Average & ss & Welch & P \\
\hline \multirow{2}{*}{ Happines } & Good & 1723 & 3.23 & .516 & \multirow{2}{*}{0.177} & .000 \\
S & Bad & 85 & 2.98 & .617 & & \\
& Average & 327 & 3.00 & .561 & & \\
\hline
\end{tabular}

Before one-way ANOVA was applied, variations homogeneity test was applied. As variations determined as not homogenous (Levene statistics =5.700; ss1=2; sd2=2132; $<<0.01$, see also Table 9), Welch test is applied.

According to the results, there is a statistical difference in happiness scores of students in their families' financial situation. ( $\mathrm{W}=28.177$; $\mathrm{p}>0,001$; see also Table 10).

Table 11. Results of Tamhane Test: Difference in Happiness Scores depending on Financial of Status of Family

\begin{tabular}{|c|c|c|c|c|}
\hline Financial Status & Financial Status & Mean difference & Std. Error & $\mathbf{p}$ \\
\hline$\overline{\text { Good }}$ & - $\quad \mathrm{Bad}$ & .25 & .068 & .001 \\
\hline Good & - Average & .23 & .033 & .000 \\
\hline$\overline{\mathrm{Bad}}$ & - $\quad$ Average & -.03 & .073 & .977 \\
\hline
\end{tabular}

3.e Does Students' Happiness Differ According to Whether Their Mother Is Employed?

Table 12. difference in happiness depending on the mother's employment

\begin{tabular}{llllllll}
\hline & $\begin{array}{l}\text { Mother's } \\
\text { employment }\end{array}$ & & & & & & \\
& & N & Mean & ss & t & sd & p \\
\hline \multirow{2}{*}{ Happiness } & Yes & 651 & 3.16 & .551 & -1.705 & 2069 & .088 \\
& No & 1420 & 3.20 & .523 & & &
\end{tabular}

Average happiness score of students whose mother is working and happiness level of students whose mother is unemployed are compared through an unpaired t-test. According to results, there is no significant difference in the happiness score of students whose mother is working and a student whose mother is not working $(\mathrm{t}=-1.075$; $\mathrm{p}>0.05$; see also Table 12).

\section{3.f Does Happiness of Students Differ According to Their Mother's Occupation?}

Occupation of student's mothers consists of 3 different professions such that civil servant, labourer and housewife. 98 students did not answer the question about their mother's occupation. Therefore, comparisons are made based on 2071 students.

In order to test whether students' happiness varies depending on their mothers' occupation, one-way ANOVA test is applied.

Table 16. Variations Homogeneity Test for Students' mother's occupation

\begin{tabular}{lllll}
\hline & Levene Statistics & sd1 & sd2 & P \\
\hline Happiness & 1.800 & 2 & 2068 & .166 \\
\hline
\end{tabular}

Table 17. Difference in happiness score of students depending on their mothers' occupation

\begin{tabular}{|c|c|c|c|c|c|c|}
\hline & Mother's Occupation & $\mathbf{N}$ & Mean & SS & $\mathbf{F}$ & $\mathbf{P}$ \\
\hline \multirow{3}{*}{$\begin{array}{l}\text { Happines } \\
\mathrm{s}\end{array}$} & Civil servant & 86 & 3.25 & .536 & \multirow{3}{*}{3.087} & \multirow{3}{*}{.066} \\
\hline & Louberer & 565 & 3.14 & .552 & & \\
\hline & House wife & 1420 & 3.20 & .523 & & \\
\hline
\end{tabular}


Before one-way ANOVA was applied, variations homogeneity test had applied. As variations determined as homogenous (Levene statistics $=1.800 ; \mathrm{ss} 1=2 ; \mathrm{sd} 2=2068 ; \mathrm{p}<0.05$, see also Table 16), F test is applied.

According to the results, there is no significant statistical difference in happiness scores of students depending on their mothers' occupation ( $\mathrm{F}=3.087 ; \mathrm{p}>0,05$; see also Table 17).

\section{3.g Does Students' Happiness Differ According to Whether Their Father Is Employed?}

Average happiness score of students whose father is working and happiness level of students whose father is unemployed are compared through an unpaired t-test. 73 students did not answer the question of whether their father is working. Therefore, comparisons are made based on 2096 students.

Table 18. Difference in happiness according to fathers' employment

\section{Father's}

employment

\begin{tabular}{|c|c|c|c|c|c|c|c|}
\hline & & $\mathbf{N}$ & Mean & SS & $\mathbf{t}$ & sd & p \\
\hline \multirow{2}{*}{ Happiness } & Yes & 2036 & 3.19 & .530 & \multirow[t]{2}{*}{2.265} & \multirow[t]{2}{*}{2094} & \multirow[t]{2}{*}{.024} \\
\hline & No & 60 & 3.03 & .588 & & & \\
\hline
\end{tabular}

According to results, there is a significant difference in the happiness score of students whose father is working and a student whose father is not working ( $t=2,265 ; \mathrm{p}>0.05$; see also Table 18$)$.

Hence, the level of happiness of students whose father is working is 3,19 whereas the level of happiness of students whose father is not working is 3,03.

\section{3.h Does Happiness of Students Differ According to Their Father's Occupation?}

Occupation of student's mothers consists of 4 different professions such that civil servant, labourer, unemployed and retired. 73 students did not answer the question about their Father's occupation. Therefore, comparisons are made based on 2096 students.

In order to test whether students' happiness varies depending on their fathers' occupation, one-way ANOVA test is applied.

Table 19. Variations Homogeneity Test for Students' fathers' occupation

\begin{tabular}{lllll}
\hline & Levene Statistics & sd1 & sd2 & p \\
\hline Happiness & 1.369 & 3 & 2092 & .251
\end{tabular}

Table 20. Difference in happiness score of students depending on their fathers' occupation

\begin{tabular}{|c|c|c|c|c|c|c|}
\hline & Father's Occupation & $\mathbf{N}$ & Mean & SS & $\mathbf{F}$ & $\mathbf{p}$ \\
\hline \multirow{4}{*}{$\begin{array}{l}\text { Happines } \\
\mathrm{s}\end{array}$} & Civil Servant & 187 & 3,18 & ,573 & \multirow{4}{*}{3,974} & \multirow{4}{*}{,008 } \\
\hline & Labourer & 1802 & 3,20 & ,524 & & \\
\hline & Unemployed & 56 & 3,07 & ,593 & & \\
\hline & Retired & 51 & 2,96 & ,542 & & \\
\hline
\end{tabular}

Table 21. Scheffe test results: Difference in happiness score of students depending on their fathers' occupation

\begin{tabular}{|c|c|c|c|c|c|}
\hline $\begin{array}{l}\text { Fathers' } \\
\text { Occupation }\end{array}$ & & $\begin{array}{l}\text { Father's } \\
\text { Occupation }\end{array}$ & Mean Difference & Std. Error & $\mathbf{p}$ \\
\hline Civil servant & - & labourer &,- 01 & ,040 & ,996 \\
\hline Civil servant & - & labourer &, 10 & ,080 & ,686 \\
\hline Civil servant & - & Retired & ,23 & 083 & ,062 \\
\hline Labourer & - & Unemployed &, 11 & ,072 &, 519 \\
\hline Labourer & - & Retired & ,24 & ,075 & ,019 \\
\hline Labourer & - & Retired &, 13 & , 102 & ,665 \\
\hline
\end{tabular}


Before one-way ANOVA was applied, variations homogeneity test was applied. As variations determined as homogenous (Levene statistics $=1.369 ; \mathrm{sd} 1=3 ; \mathrm{sd} 2=2092 ; \mathrm{p}<0.05$, see also Table 19), $\mathrm{F}$ test is applied.

According to the results, there is a significant statistical difference in happiness scores of students depending on their fathers' occupation ( $F=3.974 ; \mathrm{p}>0,01$; see also Table 20). In order to determine the difference in groups, Scheffe test was applied (see also Table 21)

According to the result of Scheffe test, only the happiness level of students whose father is labourer is significantly higher than that of students whose father is retired.

\section{3.i Does Happiness of Students Differ According to Whether Their Parents Get Along Well?}

Average happiness score of students whose parents are getting along well and those of parents who are not getting along well are compared through a t-test.

70 students did not answer the question about their parents. Therefore, comparisons were based on 2099 students.

Table 22. difference in happiness according to status of getting along of parents

\begin{tabular}{|c|c|c|c|c|c|c|c|c|}
\hline & $\begin{array}{l}\text { Status } \\
\text { getting } \\
\text { along } \\
\text { parents }\end{array}$ & $\begin{array}{l}\text { of } \\
\text { of }\end{array}$ & $\mathbf{N}$ & Mean & SS & $\mathbf{t}$ & sd & $\mathbf{p}$ \\
\hline \multirow{2}{*}{ Happiness } & Evet & & 1939 & 3,21 &, 514 & 6,108 & 2097 & ,000 \\
\hline & No & & 160 & 2,95 & 643, & & & \\
\hline
\end{tabular}

According to results, there is a statistical difference in students' happiness scores between students whose parents are getting along well and students whose parents are not getting along well $(t=6.108 ; \mathrm{p}<0.001$; see also Table 22)

According to this, the happiness level of students whose parents are getting along well (3.21) is higher than those parents are not getting along well (2.95).

\section{3.j Does Happiness of Students Differ According to Whether Their Parents Are Divorced?}

Average happiness score of students whose parents are divorced and those of parents who are not divorced are compared through an unpaired t-test.

65 students did not answer the question about their parent's separation status. Therefore, comparisons were based on 2104 students.

Table 23. Difference in happiness according to whether parents are separated

\begin{tabular}{llllllll}
\hline & $\begin{array}{l}\text { Status of } \\
\text { separation } \\
\text { of parents }\end{array}$ & N & Mean & ss & t & sd & p \\
\hline \multirow{2}{*}{ Happiness } & Yes & 187 & 3,03 &, 60930 & $-4,231$ & 2102 &, 000 \\
& No & 1917 & 3,20 &, 52404 & & & \\
\hline
\end{tabular}

According to results, there is a statistical difference in students' happiness scores between students whose parents are divorced and students whose parents are not divorced $(\mathrm{t}=-4.231 ; \mathrm{p}<0.001$; see also Table 23)

According to this, the happiness level of students whose parents are not divorced $(3,20)$ is higher than the that of students whose parents are divorced (3.03).

\section{Discussion}

This study aimed to determine the happiness levels of school children who are from 3rd to 12th grade and variables affecting their happiness levels as well as giving suggestions to people who are responsible to raise children. The five top subjects make the student happy the most is "Enjoying being with other people", "Having self-confidence", "Wanting to go to school", "Having fun", "Feeling a school is a safe place". Gilman and Huebner's study in 2006 supports the results of this study by illustrating there is a correlation between having self-confidence and being happier. It was expected that Feeling the school is a safe place, having fun and being together with friends are already directly related to being happy. 
The five top subjects making students unhappy can be listed as following; "being tired", "confusion", "having a headache", "being nervous", "being unpleasant". The fact that the number of sample space is 2180 is so high that it is necessary to focus on the causes of these problems.

When how different factors such as grade, number of siblings, whether they are the eldest or youngest child in the family, financial situation of family, whether mother is employed, mother's occupation, whether father is employed, father's occupation, whether parents are getting along well, whether parents are divorced analysed in terms of affecting students' happiness score;

It can be seen that students get less happy as they enrol in a higher grade. The study of Chui and Wong in 2016 supports the idea that the level of happiness decrease as ageing. Problems arising due to blue age, having more expectations during this period and maybe the most important heavy responsibility of entrance examination of high school and university might be the reason of decrease in happiness level as ageing (Andersen \& Teicher, 2008 ; Davey, Yucel, \& Allen, 2008; Park, 2004).

There is no significant relationship between the number of siblings, whether they are eldest or youngest sibling and happiness score coincide with the results of studies done in this area (Huebner \& Alderman, 1993; Huebner, 1991; Gilman \& Huebner, 2006).

While there is no relationship with School Children Happiness Scale scores and whether a mother is employed, children whose father is unemployed have low happiness score. This situation can be explained by the high number of unemployed mothers in Turkey. When how employment type of fathers' affect happiness score is analysed, the happiness score is higher when a father is a labourer compared to when a father is retired. In Turkey, the level of income of retired people is less than that of a labourer. However, research showing happiness comes before the level of income indicates that there might be other factors.

Students whose parents are not getting along well and divorced are less happy than the students whose parents are getting along well and together is an important finding as rates of divorce has increased rapidly compared to previous years. However, the study of Chui and Wong in 2016 shows that happiness of children is not affected by the divorce of their parents. This difference in results might be because of cultural differences or divorcing period is managed well for the participant students in the Chui and Wong study. Comparison studies conducted in different cultures might contribute to making healthy comments on this.

Controlling divorce is highly difficult. However, parents during their marriage, communication and management of divorce period should be managed so that harm to children will be minimized. This can be considered helpful. Regarding this matter, parents can receive regular educational lessons as it is hard to anticipate when one will be divorced.

In summary, parents and teachers have a great responsibility in raising happy individuals. Parents and teachers should be role models in forming a healthy environment which encourages positive thinking, being hopeful for future plans and creating memorable moments based on the studies in Positive Psychology. According to the result of the study, subjects making students happy the most are "Enjoying being with other people", "Having self-confidence", "Having fun", "Feeling a school is a safe place". These should be taken into consideration so that student could be happier and more successful if there is a healthy environment for them to have fun besides learning and spending nice time with their friends. To make this possible teachers and parents in need of systematic training courses.

\section{References}

Andersen, S. L., \& Teicher, M. H. (2008). Stress, sensitive periods and maturational events in adolescent depression. [Review]. Trends in Neurosciences, 31(4), 183-191. https://doi.org/10.1016/j.tins.2008.01.004

Cheng, H., \& Furnham, A. (2002). Personality, peer relations, and self-confidence as predictors of happiness and loneliness. [Article]. Journal of Adolescence, 25(3), 327-339. https://doi.org/10.1006/jado.2002.0475

Chui, W. H., \& Wong, M. Y. (2016). Gender differences in happiness and life satisfaction among adolescents in Hong Kong: Relationship sand self-concept. Social Indicators Research, 125(3), 1035-1051. https://doi.org/10.1007/s11205-015-0867-z

Davey, C. G., Yucel, M., \& Allen, N. B. (2008). The emergence of depression in adolescence: Development of the prefrontal cortex and the representation of reward. [Review]. Neuroscience and Biobehavioral Reviews, 32(1), 1-19. https://doi.org/10.1016/j.neubiorev.2007.04.016

Deci, E. L., \& Ryan, R. M. (2000). The "what" and "why" of goal pursuits: human needs and the self determination of behavior. Psychological Inquiry, 11(4), 227-268. https://doi.org/10.1207/S15327965PLI1104_01 
Deneve, K. M., \& Cooper, H. (1998). The Happy personality: a meta analysis of personality traits andsubjective well-being. Psychological Bulletin, 124(2), 197-229. https://doi.org/10.1037/0033-2909.124.2.197

Diener, E. (2000). Subjective well-being. American Psychologist, 55(1), 34-39. https://doi.org/10.1037/0003-066X.55.1.34

Diener, E., Oishi, S., \& Lucas, R. E. (2003). Personality, culture, and subjective well-being: Emotional and cognitive evaluations of life. [Review]. Annual Review of Psychology, 54, 403-425. https://doi.org/10.1146/annurev.psych.54.101601.145056

Emmons, R. A., \& Shelton, C. M. (2002). “Gratitude and the Science of Positive Psychology”, In C. R. Snyder-Shane J. Lopez (Eds), Handbook of Positive Psychology, Oxford University Press, New York, 459-471.

Eryilmaz, A. (2012). A Model for Subjective Well-Being in Adolescence: Need Satisfaction and Reasons for Living. [Article]. Social Indicators Research, 107(3), 561-574. https://doi.org/10.1007/s11205-011-9863-0

Gilman, R., \& Huebner, E. S. (2006). Characteristics of adolescents who report very high life satisfaction. [Article]. Journal of Youth and Adolescence, 35(3), 311-319. https://doi.org/10.1007/s10964-006-9036-7

Holder, M. D., \& Coleman, B. (2009). The Contribution of Social Relationships to Children's Happiness. [Article]. Journal of Happiness Studies, 10(3), 329-349. https://doi.org/10.1007/s10902-007-9083-0

Huebner, E. S. (1991). Correlates of life satisfaction in children. School Psychology Quarterly, 6, 103-111. https://doi.org/10.1037/h0088805

Huebner, E. S., \& Alderman, G. L. (1993). Convergent and Discriminant Validation Of A Childrens Life Satisfaction Scale - Its Relationship To Self-Reported And Teacher-Reported Psychological-Problems And School Functioning. [Article]. Social Indicators Research, 30(1), 71-82. https://doi.org/10.1007/BF01080333

Knutson, B., Taylor, J., Kaufman, M., Peterson, R., \& Glover, G. (2005). Distributed neural representation of expected value. [Article]. Journal of Neuroscience, 25(19), 4806-4812. https://doi.org/10.1523/JNEUROSCI.0642-05.2005

Kubzansky, L. D., Sparrow, D., Vokonas, P., et al. (2004). Optimism and pessimism in the context of health: Bipolar opposites or separate constructs? Personality and Social Psychological Bulletin, 30, 943-956. https://doi.org/10.1177/0146167203262086

Lyubomirsky, S., Sheldon, K. M., \& Schkade, D. (2005). Pursuing happiness: The architecture of sustainable change. Review of General Psychology, 9(2), 111-131. https://doi.org/10.1037/1089-2680.9.2.111

Myers, D. G., \& Diener, E. (1995). Who is happy? Psychological Science, 6, 10-15. https://doi.org/10.1111/j.1467-9280.1995.tb00298.x

Park, N. (2004). The role of subjective well-being in positive youth development. [Article; Proceedings Paper]. Annals of the American Academy of Political and Social Science, 591, 25-39. https://doi.org/10.1177/0002716203260078

Rolls, E. T., Kringelbach, M. L., Araujo, I. E. T. (2003). Different representations of pleasant andunpleasant odors in the human brain Eur. J. Neurosci., 18(2003), 695-703. https://doi.org/10.1046/j.1460-9568.2003.02779.x

Shoshani, A., \& Steinmetz, S. (2013). Positive psychology at school: A school based intervention to promote adolescents' mental health and well-being. Journal of Happiness Studies, 1-23, Advance online publication. https://doi.org/10.1007/s10902-013-9476-1

Telef, B. B. (2014). Validity and reliability study of happiness inventory of school children. International Journal of Educational Sciences, 6(1), 130-143.

Uusitalo-Malmivaara, L., \& Lehto, J. E. (2013). Social Factors Explaining Children's Subjective Happiness and Depressive Symptoms. [Article]. Social Indicators Research, 111(2), 603-615. https://doi.org/10.1007/s11205-012-0022-z

\section{Copyrights}

Copyright for this article is retained by the author(s), with first publication rights granted to the journal.

This is an open-access article distributed under the terms and conditions of the Creative Commons Attribution license which permits unrestricted use, distribution, and reproduction in any medium, provided the original work is properly cited. 